\title{
Control of Risk Factors for Cardiovascular Disease Among Adults with Previously Diagnosed Type 2 Diabetes Mellitus: A Descriptive Study from a Middle Eastern Arab Population
}

\author{
Jawad A Al-Lawati ${ }^{1}$, Mohammed N. Barakat ${ }^{1}$, Ibrahim Al-Zakwani*,2,3, Medhat K. Elsayed ${ }^{4}$, \\ Masoud Al-Maskari ${ }^{5}$, Nawar M Al-Lawati ${ }^{6}$ and Ali Jaffer Mohammed ${ }^{7}$ \\ ${ }^{1}$ Department of Non-communicable Diseases Surveillance and Control, Ministry of Health, Muscat, Oman \\ ${ }^{2}$ Department of Pharmacology \& Clinical Pharmacy, College of Medicine \& Health Sciences, Sultan Qaboos Univer- \\ sity, Muscat, Oman \\ ${ }^{3}$ Gulf Health Research, Muscat, Oman \\ ${ }^{4}$ Department of Statistics, Directorate General of Planning, Ministry of Health, Muscat, Oman \\ ${ }^{5}$ Department of Medicine, College of Medicine \& Health Sciences, Sultan Qaboos University, Muscat, Oman \\ ${ }^{6}$ Mutrah Health Center, Ministry of Health, Muscat, Oman \\ ${ }^{7}$ Directorate General of Health Affairs, Ministry of Health, Muscat, Oman
}

\begin{abstract}
Background: Despite the high burden of type 2 diabetes mellitus (T2DM) in Oman, there are scarce data from a nationally representative sample on the level of glycaemia and other cardiovascular (CVD) risk factor control.

Objective: To estimate the proportion of patients with T2DM at goal for glycaemia and CVD risk factors using the National Diabetes Guidelines (NDG) and the American Diabetes Association (ADA) clinical care guidelines; and to assess the quality of selected services provided to patients with T2DM.

Methods: A sample of 2,551 patients ( $47 \%$ men) aged $\geq 20$ years with T2DM treated at primary health care centers was selected. Patient characteristics, medical history and treatment were collected from case notes, Diabetes Registers and computer frameworks including the use of the last 3 laboratory investigations results and blood pressure (BP) readings recorded in 2007.

Results: The overall mean age of the cohort was $54 \pm 13$ years with an average median duration of diabetes of 4 (range 2 to 6) years. Over $80 \%$ of patients were overweight or obese (body mass index (BMI) of $\geq 25 \mathrm{Kg} / \mathrm{m}^{2}$ ). Sixty-nine percent were on oral anti-diabetic medication, $52 \%$ on anti-hypertensives and $40 \%$ on lipid lowering drugs. Thirty percent of patients were at goal for glycosylated haemoglobin level $(<7 \%), 26 \%$ for BP (systolic/diastolic $<130 / 80 \mathrm{mmHg}$ ), $55 \%$ for total cholesterol $(<5.2 \mathrm{mmol} / \mathrm{l}), 4.5 \%$ for low-density lipoprotein cholesterol $(<1.8 \mathrm{mmol} / \mathrm{l}), 52 \%$ for high-density lipoprotein cholesterol ( $>1 \mathrm{mmol} / 1$ for men, $>1.3 \mathrm{mmol} / \mathrm{l}$ for women), and $61 \%$ for triglycerides $(<1.7 \mathrm{mmol} / \mathrm{l})$. Over $37 \%$ had microalbuminuria and $5 \%$ had diabetic nephropathy.
\end{abstract}

Conclusion: Control of hyperglycaemia and other CVD risk factor appears to be suboptimal in Omani patients with T2DM and need to be addressed in the triad of patient, physician and health system.

Keywords: Diabetes mellitus, glycosylated hemoglobin Alc, blood pressure, low-density lipoprotein cholesterol, high-density lipoprotein cholesterol, triglycerides, Oman.

\section{INTRODUCTION}

Diabetes (DM) is becoming an increasingly important cause of cardiovascular disease (CVD). Two-thirds to three-

\footnotetext{
*Address correspondence to this author at the Department of Pharmacology \& Clinical Pharmacy, College of Medicine \& Health Sciences, Sultan Qaboos University, P.O. Box 35, Al-Khodh, PC-123, Sultanate of Oman; Tel: +968-2414-4420; Fax: +968-2414-4430;

E-mail: ial_zakwani@yahoo.com
}

quarters of patients with DM eventually die of CVD [1] Morbidity and mortality from microvascular (retinopathy, neuropathy and nephropathy) and macrovascular complications (coronary artery disease, stroke and peripheral vascular disease) increases by 2 to 4 fold in individuals with DM compared with those without DM [2]. However, these complications are not inevitable and can be prevented or delayed by tighter glycaemic, blood pressure (BP) [3, 4] and favorable lipid profile [5]. 
DM, however, remains highly prevalent in Arab countries of the Middle East. The International Diabetes Federation has ranked four Arab states, namely United Arab Emirates, Saudi Arabia, Bahrain, Kuwait and Oman, among the top 10 countries with the highest prevalence of DM in the World [6]. This trend is projected to continue until 2030 [6]. In Oman (population of $\sim 2$ million inhabitants), 2 surveys, conducted 10 years apart, have shown a high prevalence of DM. In 1991, DM affected $12.2 \%$ of Omanis aged 30-64 years $[7,8]$. A decade later, the prevalence increased to $16.1 \%$ in the same age group [8]. Yet, there are no national data on glycaemic control, prevalence of CVD risk factors or quality of care provided to patients with DM in Oman.

The purpose of this cross-sectional study was to: a) measure the proportion of patients achieving level of glycaemic and cardiometabolic risk factors control in a nationally representative sample of subjects with type $2 \mathrm{DM}$ (T2DM) using 2 published guidelines: the National Diabetes Guidelines (NDG) and the American Diabetes Association (ADA) clinical care guidelines $[9,10]$, and, b) to assess the quality of services provided to patients with DM.

\section{METHODS}

\section{Study Population}

The study population was all Omanis aged $\geq 20$ years with a diagnosis of T2DM and being followed-up at primary health care centres (PHCs). A 2 stage cluster sampling technique was used in which each medical institution was considered as a primary sampling unit. Of the total 180 PHCs, centres with less than 20 registered diabetic patients were excluded $(\mathrm{n}=54)$. Seeking a precision of $20 \%$ of the expected frequency, $95 \%$ confidence level (CI), and applying a design effect of 1.2 with a drop-out rate of $20 \%$, the sample size was estimated to be 2,510 . Given that the average size of each cluster was 171 patients, 16 clusters were chosen from a total of 126 over 8 strata of varying sizes using simple random sampling method. The methods on the same cohort, but on a related topic, have already been published elsewhere [11].

All patients in the selected clusters were included in the study. Data collection was limited to the year 2007. Diabetes Registers (representing hard copy records which trace summary of patient clinical parameters at initial diagnosis and each subsequent annual visit) were utilized to collect data. In addition, computer frameworks, where available, were used to complement the data collection process. Data were collected mainly by the clinic nurse and supervised by the physician conducting the local DM clinic. The data collection phase was completed by 2008 .

Collected data included patient characteristics, past medical history of CVD, history of selected DM complications, anthropometric measurements and medication, outpatient department (OPD) procedures and parameters related to DM and CVD risk factor control. For systolic and diastolic BP and laboratory measurements for glycosylated haemoglobin (HbAlc), total cholesterol, triglycerides, low density lipoprotein cholesterol (LDL-C), high density lipoprotein cholesterol (HDL-C), urine albumin, creatinine and urine albumin-creatinine ratio, the average of the most recent 3 readings in the 2007 were recorded.

The NDG published by the Omani Health Ministry [9] and the ADA standards of medical care for patients with DM [10] were used to define desirable levels of $\mathrm{HbAlc}, \mathrm{BP}$ and serum lipids such that: good glycaemic control was defined as HbAlc $<7 \%$; hypertension as systolic and/or diastolic BP $<130 / 80 \mathrm{mmHg}$; total serum cholesterol $\leq 5.2 \mathrm{mmol} / \mathrm{l}$. The 2 guidelines, however, differed on lipid profile cut-points. Where such differences existed, data were analyzed and presented for both cut-point values: thus desired LDL-C was defined as $<2.6 \mathrm{mmol} / 1$ (for NDG) and $<1.8 \mathrm{mmol} / \mathrm{l}$ (for ADA); serum triglycerides $<2.3 \mathrm{mmol} / 1$ (for $\mathrm{NDG}$ ) and $<1.7$ $\mathrm{mmol} / \mathrm{l}$ (for ADA); HDL $>0.9 \mathrm{mmol} / 1$ for both genders (NDG) and $>1.0 \mathrm{mmol} / 1$ in men and $>1.3 \mathrm{mmol} / 1$ in women (for ADA). Body mass index (BMI; $\mathrm{kg} / \mathrm{m}^{2}$ ) was categorized as per the World Health Organization guidelines [12]; normal weight (BMI $<25)$, over weight $(25 \leq \mathrm{BMI} \leq 29.9$ $\mathrm{kg} / \mathrm{m}^{2}$ ) and obesity (BMI $\geq 30 \mathrm{~kg} / \mathrm{m}^{2}$ ). Current tobacco use was defined as using tobacco at the time of the survey. Urine dipstick was used to measure the presence or absence of urine albumin. Estimated glomerular filtration rate (eGFR) was calculated using the Modification of Diet in Renal Disease (MDRD) study equation [13]. Microalbuminuria was defined as urine albumin-to-creatinine ratio (ACR) $\geq 2.5$ $\mathrm{mg} / \mathrm{mmol}$ for men and $\geq 3.5 \mathrm{mg} / \mathrm{mmol}$ for women [14]. Nephropathy was defined as ACR $>25 \mathrm{mg} / \mathrm{mmol}$ for both genders. A history of CVD was defined as history of angina, myocardial infarction or coronary artery procedure (bypass graft/percutaneous transluminal coronary angioplasty).

\section{Statistical Analysis}

Descriptive statistics were used to describe the data. For categorical variables, frequencies and percentages were reported. Differences between groups were analyzed using Pearson's chi-squared tests. For continuous variables, means and standard deviations were presented. Resource utilization of service indicators was presented using the median and interquartile range. Numbers of resource use were also presented as categories below or above the median. Differences between groups were analyzed using the Student's t-test. Significance was set at the 2-tailed 0.05 level. Analysis was performed using Stata (version 11, Stata Corporation, Tx, USA).

\section{RESULTS}

\section{Patient Characteristics}

The study population consisted of 2,551 patients (47\% men) with previously diagnosed T2DM from 8 regions of Oman, excluding pregnant women $(\mathrm{n}=33)$ and those reported "uncertain" pregnancy status $(\mathrm{n}=19)$. Baseline demographic and clinical characteristics are presented in Table 1 . The overall mean age of the cohort was $54 \pm 13$ years with the median duration of DM of 4 (2-6) years, with no significant differences among the genders ( 4.7 vs 4.6 years; $p$ $=0.51)$. Women were significantly more likely to be obese (31 vs $\left.28 \mathrm{~kg} / \mathrm{m}^{2} ; p=0.001\right)$, hypertensive ( 55 vs $48 \%$; $p=$ 0.001 ), on oral anti-diabetic (71 vs 67\%; $p=0.050)$ and antidyslipidemic (56 vs $43 \% ; p=0.001$ ) than men. Men, 
Table 1. Baseline Characteristics, Co-morbidity and History of Medication use in Patients with Type 2 Diabetes, Oman, 2008.

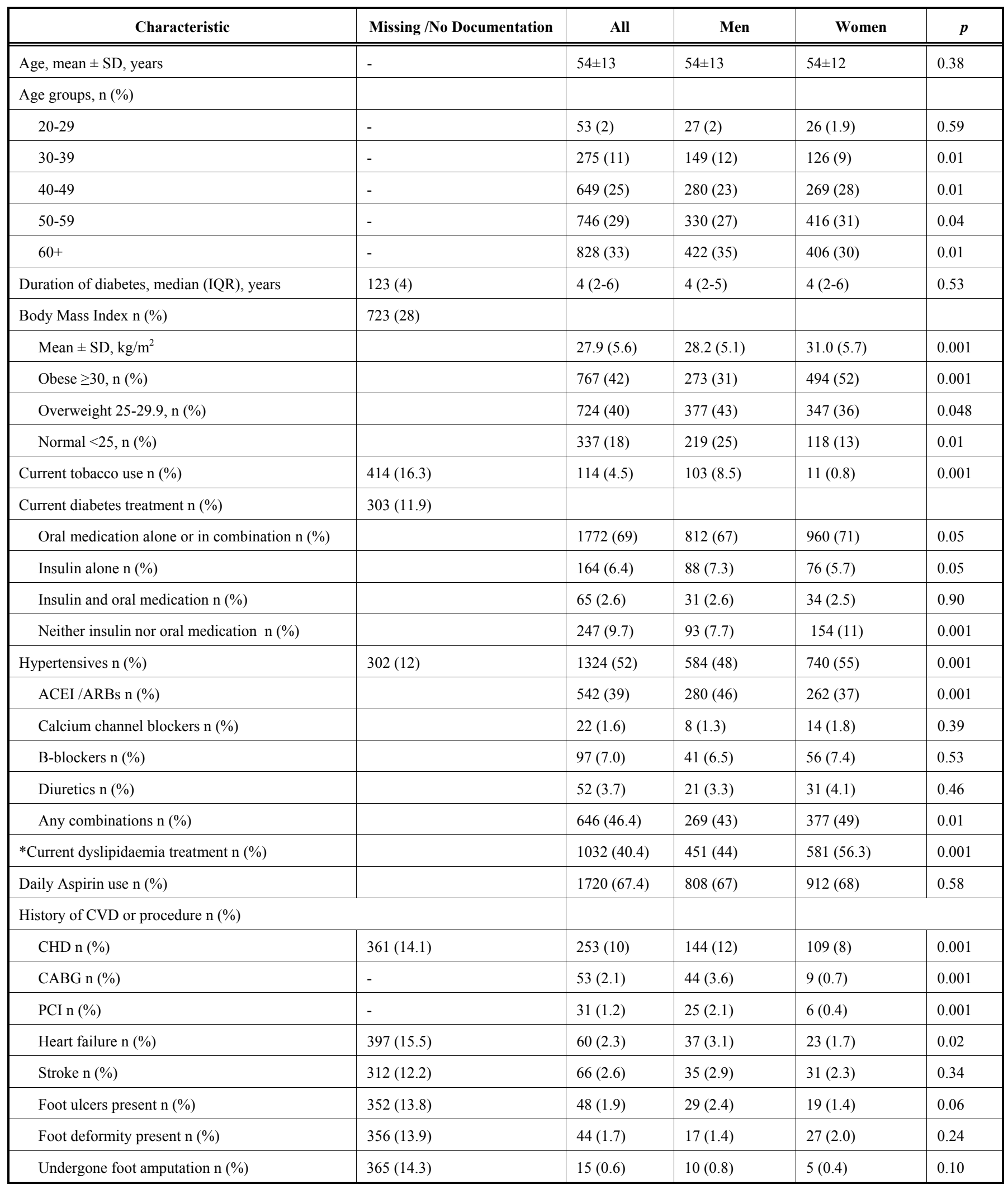

*percentages are of the total with the characteristic; SD, standard deviation; IQR, interquartile range; CVD, cardiovascular disease; CHD, coronary heart diseases; $\mathrm{CABG}$, coronary artery bypass graft; PCI, percutaneous coronary intervention; ACEI, angiotensin converting enzyme inhibitor; ARBs angiotensin II receptor antagonists. 
on the other hand, were more likely to be overweight (43 vs $36 \% ; p=0.048)$, smokers ( 8.5 vs $0.8 \% ; p=0.001)$, with positive history of coronary heart disease (12 vs $8 \%$; $p=$ $0.001)$. Sixty-seven percent $(n=1,720)$ of the patients were prescribed aspirin.

The median number of OPD visits, weight measurements and BP measurements was 6 per year as shown in Table 2. Over $42 \%$ of patients were seen 6 times or more in a year for consultations. During these visits, $34 \%$ had weight and $44 \%$ had their BP measured 6 times or more per year. One in 10 patients did not have their fundi dilated during eye examination, urine albumin, serum creatinine, $\mathrm{HbAlc}$, blood lipids measured or an electrocardiograph (ECG) taken during the study year. Data was not documented for various variables ranging from a minimum of $11.8 \%$ for BP readings to $64.3 \%$ for albumin-to-creatinine ratio during 2007 (Table 3).

The mean HbAlc was $8.3 \pm 2.1$, higher in men than women (8.4 vs $8.2 \%$; $p=0.004$ ) (Table 3). Overall, $30 \%$ of patients had HbAlc at the NDG/ADA goal $(<7.0 \%)$, and levels did not differ statistically by genders (33 vs $27 \%$; $p=$ $0.06)$. However, significantly more men than women (51 vs $44 \% ; p=0.04)$, had their HbAlc above the level where the ADA recommends focus treatment (HbA1c $>8 \%$ ) for glycaemic control. The mean systolic BP of the cohort was 131 $\pm 13 \mathrm{mmHg}$ and diastolic $80 \pm 7 \mathrm{mmHg}$. Only 1 in 4 patients were at goal for BP, based on NDG/ADA (systolic and diastolic $<130 / 80 \mathrm{mmHg}$ ). Significantly more men than women were at goal for total cholesterol (61 vs $50 \% ; p=0.001)$ and HDL-C levels ( 68 vs $40 \%$; $p=0.001$ ). Around $24 \%$ of subjects were at goal for LDL-C levels when NDG (cut-point $<2.6 \mathrm{mmol} / \mathrm{l}$ ) was used. This figure declined to just $4 \%$ when ADA recommendation $(<1.7 \mathrm{mmol} / \mathrm{l})$ was applied. Compared with women, more men had higher prevalence of microalbuminuria (44 vs $31 \% ; p=0.02$ ) and low eGFR (55vs $43 \% ; p=0.001)$.

There were only 18 patients $(0.7 \%$; $95 \%$ CI: $0.41-1.1)$ with previously diagnosed DM who achieved currently recommended goals for all risk factors ( $\mathrm{HbAlc}<7 \%$, BP $<130 / 80 \mathrm{mmHg}$, total serum cholesterol $<5.2 \mathrm{mmol} / \mathrm{l}$, LDL$\mathrm{C}<2.6 \mathrm{mmol} / \mathrm{l}$, HDL-C $>0.9 \mathrm{mmol} / \mathrm{l}$, triglycerides $<2.3$ $\mathrm{mmol} / \mathrm{l}, \mathrm{BMI}<25 \mathrm{~kg} / \mathrm{m} 2$, and non-smoker) using NDG. Only 4 individuals $(0.2 \%$; 95\% CI: $0.04-0.40)$ achieved these goals when ADA guidelines were used.

\section{DISCUSSION}

This study reports for the first time the level of control of CVD risk factors in patients with T2DM in Oman. It shows that in such patients, hyperglycaemia, hypertension, and dyslipidaemia are poorly controlled despite universally free medical care including free medication and patients seeing their local physicians almost every 2 months. Only a minute fraction $(0.2 \%)$ of patients in our study attained currently recommended levels of control for hyperglycaemia and other CVD risk factors. An earlier report suggested this figure to be $2.4 \%$ [15]. Although most patients are consulted, on average, 6 times annually, we found no significant relationship between the number of OPD visits and level of HbAlc ( $p=$ 0.83 ; data not shown). This illustrates the urgent need for more emphasis on patient education, in particular including DM health educators to PHC teams.

Compared with a similar study conducted in 2005 involving 430 diabetic patients in Muscat, the capital city of Oman [15], our study shows higher proportions of patients reaching recommended HbA1c level (30 vs 24\%) and favorable lipid profile (total cholesterol 55 vs 40\%; LDL-C 25 vs 15\%; and HDL-C 49 vs 41\%). The improved glycaemic control and lipid profile in our study could be attributed to a policy decision made in 2006, when insulin, statins and BP lowering drugs were made widely available in all PHC centers throughout Oman instead of only being prescribed by physicians in secondary and tertiary hospitals.

Hypertension is associated with DM, and may be related to underlying diabetic nephropathy or to coexisting essential hypertension [16]. In our study only $25 \%$ of patients were at goal $(<130 / 80 \mathrm{mmHg})$ for optimal BP control compared with $48 \%$ reported by Al-Mandhari et al [15]. The difference could partially be attributed to the fact that the former study covered a larger national sample while the latter covered only 1 region in the capital, Muscat. Control of hypertension remains a challenge in both developing and developed nations. The mean BP in the United States has decreased from $138 / 73 \mathrm{mmHg}$ in 1994 to $135 / 71 \mathrm{mmHg}$ in 2000 , and in Sweden (from $141 / 77 \mathrm{mmHg}$ in 2005 to $136 / 76 \mathrm{mmHg}$ in 2009) $[17,18]$. Over the same periods, $<38 \%$ of patients in the US and $54 \%$ in Sweden reached goal $(<130 / 80 \mathrm{mmHg}$ and $\leq 140 / 90 \mathrm{mmHg}$, respectively).

Microalbuminuria independently predicts traditional risk factors and CVD mortality and events in patients with DM [19]. An earlier study of microalbuminuria of patients with DM attending a university hospital in Oman reported the prevalence of incipient nephropathy to be $27 \%$ [20]. Our study, covering primary care centres, shows higher figure (37\%) similar to rates reported from Saudi Arabia (41\%) and India $(36 \%)[21,22]$. Over a decade ago, the incidence of end-stage renal disease (ESRD) in Oman was reported to be $\sim 120$ per million inhabitants annually with $14.5 \%$ of cases attributed to DM [23]. This is likely to have increased since the number of renal dialysis units and patients in Oman have more than doubled from 10 units with 345 patients in 1998 to 17 units and 872 patients in 2009 [24]. With current prevalence rates of DM, the burden of ESRD attributable to DM in Oman is likely to have increased to rates comparable to Jordan (29\%) if not more [25]. If current trends continue, Oman could expect a costly epidemic of ESRD over the next decades.

Despite compelling evidence, over the past 2 decades, from various randomized clinical trials [3-5] on the benefit of controlling hyperglycaemia and CVD risk factors in the prevention of microvascular and macrovascular complications of DM, the control of DM and associated risk factors remains poor in developed and developing countries alike. In an analysis of the National Health and Nutrition Examination Survey III (NHANES III) (1988-1998) compared to NHANES I (1999-2000) surveys, Saydah and colleagues [17] found the proportion of people with good glycaemic control ( $\mathrm{HbA} 1 \mathrm{C}<7 \%$ ) to have declined from 44 to $37 \%$ respectively. In Australia, HbAlc control levels varied from 
Table 2. Frequency of Selected Service Indicators for Subjects with Type 2 Diabetes in Primary Health Care Centres During the Year of 2008.

\begin{tabular}{|l|c|c|c|c|}
\hline \multicolumn{1}{|c|}{ Indicator measurement frequency } & Median no. of Visits/Patient/Yr & $<\mathbf{6} /$ year & $\geq 6$ / year & No Documentation (\%) \\
\hline \hline Consultations & 6 & $954(37.4)$ & $1085(42.5)$ & $512(20.1)$ \\
\hline Weight measurement & 6 & $808(31,7)$ & $867(34.0)$ & $876(34.3)$ \\
\hline Blood pressure measurement & 6 & $654(25.6)$ & $1135(44.5)$ & $762(29.9)$ \\
\hline & & Yes & No & $332(13.0)$ \\
\hline Fundus dilated during eye examination & & $1,409(55.2)$ & $809(31.7)$ & $292(11.4)$ \\
\hline Urine Albumin measured & & $1,770(69.4)$ & $488(19.1)$ & $294(11.5)$ \\
\hline Serum creatinine measured & & $1,783(69.9)$ & $473(18.5)$ & $292(11.4)$ \\
\hline Glycosylated Hb Alc $_{\text {measured }}$ & & $1,683(66.0)$ & $575(22.5)$ & $299(11.7)$ \\
\hline Lipids measured & & $1,668(65.9)$ & $581(22.8)$ & $289(11.3)$ \\
\hline Resting ECG done & & $1,661(65.1)$ & $599(23.5)$ & $291(11.4)$ \\
\hline
\end{tabular}

ECG, Electrocardiogram

Table 3. Levels of $\mathbf{H b A}_{1 \mathrm{c}}$, Blood Pressure, Lipid Profile, Renal Function and Types of Diabetic Retinopathy Among 2,551 Omanis Aged 20 Years and above with Diagnosis of Diabetes

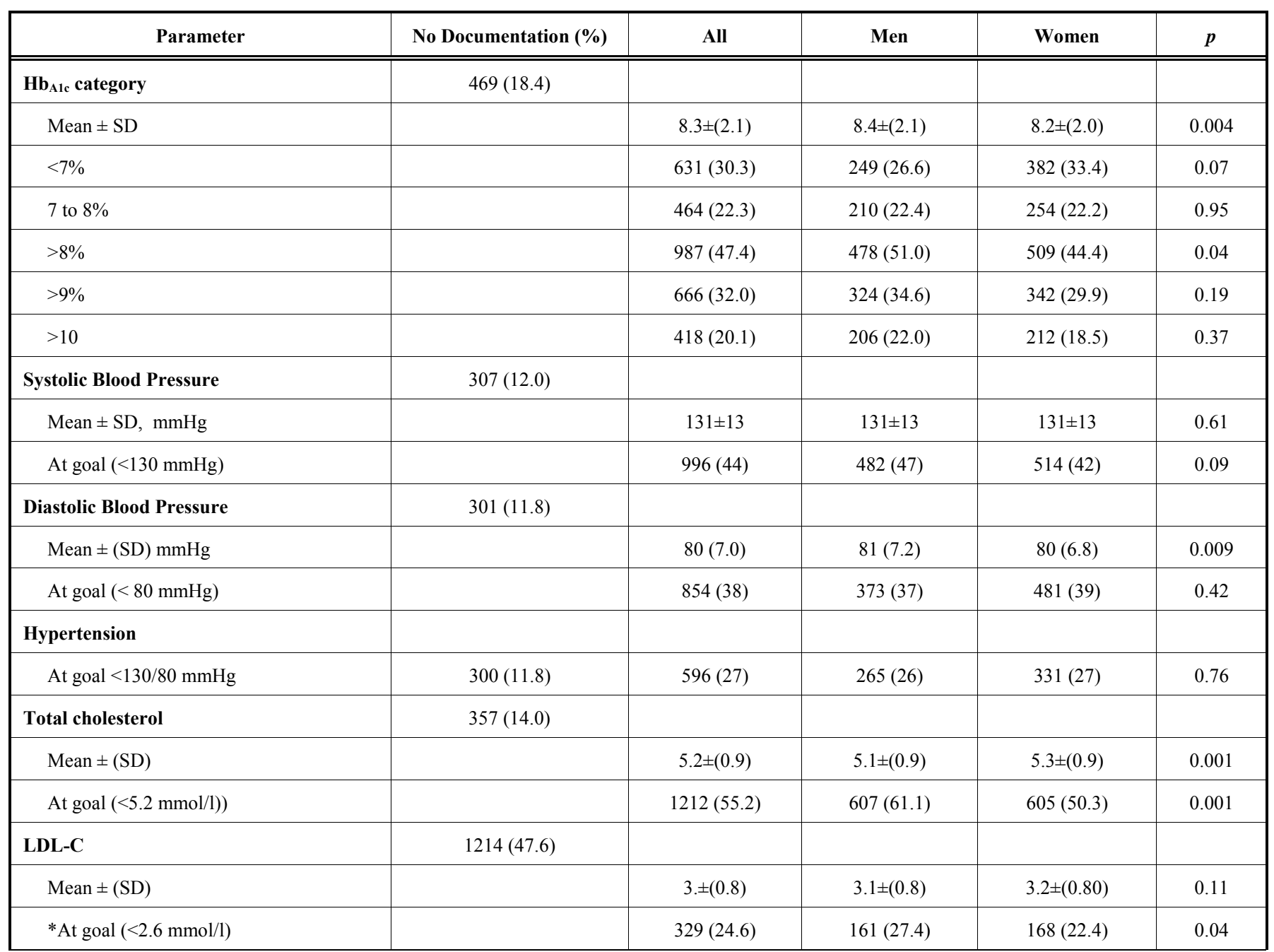


Table 3 Contd.....

\begin{tabular}{|c|c|c|c|c|c|}
\hline Parameter & No Documentationp & All & Men & Women & $p$ \\
\hline At goal $(<1.8 \mathrm{mmol} / \mathrm{l})$ & & $60(4.5)$ & $28(4.8)$ & $32(4.3)$ & 0.92 \\
\hline Mean $\pm(S D)$ & & $1.2 \pm(0.3)$ & $1.1 \pm(0.27)$ & $1.2 \pm(0.28)$ & 0.001 \\
\hline$*$ At goal $(\geq 0.9 \mathrm{mmol} / \mathrm{l})$ & & $1256(49.2)$ & $517(42.8)$ & $739(55.0)$ & 0.001 \\
\hline Triglycerides & $484(19.0)$ & & & & \\
\hline Mean $\pm(\mathrm{SD})$ & & $1.6 \pm(0.7)$ & $1.6 \pm(0.8)$ & $1.6 \pm(0.7)$ & 0.85 \\
\hline$*$ At goal $(<2.3 \mathrm{mmol} / \mathrm{l})$ & & $1737(84.0)$ & $774(83.9)$ & $963(84.2)$ & 0.86 \\
\hline At goal $(<1.7 \mathrm{mmol} / \mathrm{l})$ & & $1274(61.6)$ & $565(61.2)$ & $709(62.0)$ & 0.77 \\
\hline ACR $($ men $>2.5$, women $>3.5 \mathrm{mg} / \mathrm{mmol})$ & $1642(64.3)$ & $336(37.0)$ & $180(43.8)$ & $156(31.3)$ & 0.02 \\
\hline ACR $>25(\mathrm{mg} / \mathrm{mmol})$ & $1642(64.3)$ & $44(4.8)$ & $29(7.1)$ & $15(3.0)$ & 0.57 \\
\hline eGFR $\left(\mathrm{mL} / \mathrm{min} / 1.73 \mathrm{~m}^{2}\right)$ & $345(13.5)$ & & & & \\
\hline Mean $\pm(\mathrm{SD})$ & & $93 \pm(24.7)$ & $91 \pm(24.6)$ & $95 \pm(24.7)$ & 0.001 \\
\hline$\geq 60$ & & $2034(92.2)$ & $924(45.4)$ & $1110(54.6)$ & 0.001 \\
\hline $15-59$ & & $172(7.8)$ & $81(8.0)$ & $91(7.6)$ & 0.92 \\
\hline$<15$ & & $2(0.1)$ & $1(0.1)$ & $1(0.1)$ & - \\
\hline
\end{tabular}

*Cut-point values as per national guidelines (see ref [9]); $\mathrm{Hb}_{\mathrm{Alc}}$, glycosylated haemoglobin; SBP, systolic blood pressure; DBP, diastolic blood pressure; TC, total cholesterol; LDL-C, low density lipoprotein cholesterol; HDL-C; high density lipoprotein cholesterol; ACR, albumin creatinine ratio; eGFR, estimated glomerular filtration rate. $(\mathrm{men}>1.0$, women $>1.3 \mathrm{mmol} / \mathrm{l})$

$38 \%$ in general practice to $57 \%$ in specialist DM clinics [26], and in Finland, glycaemic control levels were as low as $25 \%$ [27]. HbA1c figures comparable to ours were reported from United Arab Emirates (31\%) and Lebanon (28\%), while lower figures were reported from Saudi Arabia (20.6\%), Kuwait (13\%) and Bahrain (11.2\%) [28-32].

Based on evidence from randomized clinical trials, various clinical guidelines recommend cut-point values for optimal levels of glycaemia, BP and lipids for patients with DM in order to prevent or delay microvascular and macrovascular complications. Yet optimal control of glycaemia, BP and lipids remain under $50 \%$ at best. Several factors have been cited to influence quality of care for people with DM, and could be divided into 3 types [33]. First, patient-related factors include patient demographics and their lifestyle including diet, physical activity and compliance with medication. Second, physician-related factors, including training, education and financial incentives for health professional to acquire self-confidence and overcome "clinical inertia" (the failure to initiate or advance therapy in a patient who is not at the evidence-based treatment goal) [34]. Alberti et al found physicians "motivation" to be significantly associated with better quality of DM care in Tunisia [33]. However, the subjective nature of the term "motivation" makes it difficult to standardize. Third, health system-related factors that could influence DM care. Al-Azri et al, [35] identified several such factors in PHC setting in Oman including shortage of Arabic language speaking nurses; unavailability of some anti-diabetic medications and educational materials; lack of continuity of care (seeing different physician over time), and unavailability of laboratory results to physicians even 2 weeks after ordering blood tests.

There have been some questions as to whether the low glycaemic control goals for patients with T2DM (such as $\mathrm{HbAlc} 6.5$ to $7 \%$ ) is evidence-based or warranted. For, findings from several clinical trials, regarding tight glycaemia are inconclusive, estimates of favorable effects were imprecise due to low rate of complications and at times contradictory [36]. For example, the UKPDS trial [37] has shown that tight glycaemic control significantly reduces all-cause and CVD mortality. In contrast, the ACCORD trial has shown that compared with standard therapy, the use of intensive therapy to target normal $\mathrm{HbAlc}$ levels for 3.5 years increased mortality and did not significantly reduce major cardiovascular events in patients with T2DM [38]. Proponents of less tight control advocate for a balanced approach where risk of complications (hyperglycaemia and death) in addition to non-compliance, social and financial burdens are considered [36]. They propose to keep HbA1c between 7 to $7.5 \%$ with estimated average glucose in the range of 8.5 to 9.5 $\mathrm{mmol} / \mathrm{l}$ for most patients. 
Accurate documentation of data in DM care is vital to continuity of care. Our study shows lack of documentation in medical records ranging from 11 (BP) to 64\% (albumin-tocreatinine ratio). Unrecorded variables related to DM care were in the range of 19 to $50 \%$ in 3 health centers in Egypt [39] and 20 to $70 \%$ in 52 general practices in the Netherlands [40]. The transition from paper run to electronic health records is currently underway in all PHC centers in Oman and is expected to improve quality of care monitoring and evaluation of risk factor control for patients with T2DM as shown elsewhere [41].

In conclusion, control of hyperglycaemia and other CVD risk factor appears to be suboptimal in Oman. Addressing health system components such as providing medical staff training, incentive to health professionals and better patient education may improve quality of DM care in Oman.

\section{ACKNOWLEGEMENT}

None Declared.

\section{DECLARATION OF CONFLICTING INTERESTS}

The authors confirms that this article content has no conflicts of interest.

\section{REFERENCES}

[1] Bloomgarden ZT. Cardiovascular disease and diabetes. Diabetes Care 2003; 26: 230-7.

[2] Kanaya AM, Grady D, Barrett-Connor E. Explaining the sex difference in coronary heart disease mortality among patients with type 2 diabetes mellitus: a meta-analysis. Arch Intern Med 2002; 162: $1737-45$.

[3] Stratton IM, Adler AI, Neil HA, et al. Association of glycaemia with macrovascular and microvascular complications of type 2 diabetes (UKPDS 35): prospective observational study. BMJ 2000; 321: 405-12.

[4] Adler AI, Stratton IM, Neil HA, et al. Association of systolic blood pressure with macrovascular and microvascular complications of type 2 diabetes (UKPDS 36): prospective observational study. BMJ 2000; 321: 412-9.

[5] Colhoun HM, Betteridge DJ, Durrington PN, et al. Primary prevention of cardiovascular disease with atorvastatin in type 2 diabetes in the Collaborative Atorvastatin Diabetes Study (CARDS): multicentre randomised placebo-controlled trial. Lancet 2004; 364: 685-96.

[6] International Diabetes Federation. IDF Diabetes Atlas Version 4. 2011 Available at: http://www.idf.org/diabetesatlas/diabetes-andimpaired-glucose-tolerance. [cited 2011 October 15].

[7] Asfour MG, Lambourne A, Soliman A, et al. High prevalence of diabetes mellitus and impaired glucose tolerance in the Sultanate of Oman: results of the 1991 national survey. Diabet Med 1995; 12: 1122-5.

[8] Al-Lawati JA, Al Riyami AM, Mohammed AJ, Jousilahti P. Increasing prevalence of diabetes mellitus in Oman. Diabet Med 2002; 19: 954-7.

[9] Ministry of Health, Sultanate of Oman. Diabetes Mellitus, Management Guidelines for Primary Health Care, Oman 2003.

[10] American Diabetes Association. Standards of medical care for patients with diabetes mellitus. Diabetes Care 2011; 34: S11-61.

[11] Al-Lawati J, Barakat MN, Al-Lawati NA, et al. Cardiovascular risk assessment in diabetes mellitus: comparison of the General Framingham Risk Profile versus the World Health Organization/International Society of Hypertension risk prediction charts in Arabs. Clinical implications. Angiology 2012. [In press].

[12] World Health Organization. Obesity: preventing and managing the global epidemic. World Health Organization WHO Technical Report Series, No. 894. Geneva: WHO; 2000.

[13] Levey AS, Coresh J, Greene T, et al. Using standardized serum creatinine values in the modification of diet in renal disease study equation for estimating glomerular filtration rate. Ann Intern Med 2006; 145: 247-54.

[14] Mogensen CE, Keane WF, Bennett PH, et al. Prevention of diabetic renal disease with special reference to microalbuminuria. Lancet 1995; 346: 1080-4.

[15] Al-Mandhari A, Al-Zakwani I, El-Shafie O, Al-Shafaee M, Woodhouse N. Quality of Diabetes Care: A cross-sectional observational study in Oman. Sultan Qaboos Univ Med J 2009; 9: 32-6.

[16] American Diabetes Association. Nephropathy in diabetes. Diabetes Care 2004; 27: S 79-83.

[17] Saydah SH, Fradkin J, Cowie CC. Poor control of risk factors for vascular disease among adults with previously diagnosed diabetes. JAMA 2004; 291: 335-42.

[18] Cederholm J, Nilsson PM. A Review of Risk Factors and Cardiovascular Disease in Diabetes Care. Eur J Cardiovasc Med 2011; 1: 21-5.

[19] Weir MR. Microalbuminuria and cardiovascular disease. Clinical J Am Soc Nephrol: 2007; 2: 581-90.

[20] Al-Futaisi A, Al-Zakwani I, Almahrezi A, et al. Prevalence and predictors of microalbuminuria in patients with type 2 diabetes mellitus: a cross-sectional observational study in Oman. Diabetes Res Clin Pract 2006; 72: 212-5.

[21] Al-Khader AA. Impact of diabetes in renal diseases in Saudi Arabia. Nephrol Dial Transplant 2001; 16: 2132-5.

[22] Varghese A, Deepa R, Rema M, Mohan V. Prevalence of microalbuminuria in type 2 diabetes mellitus at a diabetes centre in southern India. Postgrad Med J 2001; 77: 399-402.

[23] Al-Marhuby H. Renal replacement therapy in sultanate of Oman. Saudi J Kidney Dis Transplant 1998; 9: 459-60.

[24] Directorate General of Planning. Annual health report. 2009; Available at: http://www.moh.gov.om/ [Accessed November, 2011].

[25] Abdallah S, Ahmad AT, Batieha A, Ajlouni K. Diabetes mellitus: the leading cause of haemodialysis in Jordan. East Mediterr Health J 2007; 13: 803-9.

[26] Si D, Bailie R, Wang Z, Weeramanthri T. Comparison of diabetes management in five countries for general and indigenous populations: an internet-based review. BMC Health Serv Res 2010; 10: 169.

[27] Valle T, Koivisto VA, Reunanen A, Kangas T, Rissanen A. Glycemic control in patients with diabetes in Finland. Diabetes Care 1999; 22: 575-9.

[28] Alkaabi JM, Al-Dabbagh B, Ahmad S, Saadi HF, Gariballa S, Ghazali MA. Glycemic indices of five varieties of dates in healthy and diabetic subjects. Nutr J 2011; 10: 59.

[29] Al-Hussein FA. Diabetes control in a primary care setting: a retrospective study of 651 patients. Ann Saudi Med 2008; 28: 267-71.

[30] Al-Sultan FA, Al-Zanki N. Clinical Epidemiology of Type 2 Diabetes Mellitus in Kuwait. Kuwait Med J 2005; 37: 98-104.

[31] Fikree M, Hanafi B, Hussain ZA, Masuadi EM. Glycemic Control of Type 2 Diabetes Mellitus. Bahrain Med Bull 2006; 28: 105-7.

[32] Akel M, Hamadeh G. Quality of diabetes care in a university health center in Lebanon. Int J Qual Health Care 1999; 11: 517-21.

[33] Alberti H, Boudriga N, Nabli M. "Damm sokkor": factors associated with the quality of care of patients with diabetes: a study in primary care in Tunisia. Diabetes Care 2007; 30: 2013-8.

[34] Triplitt C, McGill JB, Porte D, Jr Conner CS. The changing landscape of type 2 diabetes: the role of incretin-based therapies in managed care outcomes. Journal of managed care pharmacy: J Manag Care Pharm 2007; 13: S2-16.

[35] Al-Azri M, Al-Azri H, Al-Hashmi F, Al-Rasbi S, El-Shafie K, AlManiri A. Factors Affecting the Quality of Diabetic Care in Primary Care Settings in Oman: a qualitative study on patients' perspectives. Sultan Qaboos Univ Med J 2011; 11: 207-13.

[36] Montori VM, Fernandez-Balsells M. Glycemic control in type 2 diabetes: time for an evidence-based about-face? Ann Intern Med 2009; 150: 803-8.

[37] UK Prospective Diabetes Study (UKPDS) Group. Effect of intensive blood-glucose control with metformin on complications in overweight patients with type 2 diabetes (UKPDS 34). Lancet 1998; 352: 854-65.

[38] The Action to Control Cardiovascular Risk in Diabetes Study Group. Effects of intensive glucose lowering in type 2 diabetes. N Engl J Med 2008; 358: 2545-59.

[39] Abou El-Enein NY, Abolfotouh MA. An audit of diabetes care at 3 centres in Alexandria. East Mediterr Health J 2008; 14: 636-46. 
[40] Goudswaard AN, Lam K, Stolk RP, Rutten GE. Quality of recording of data from patients with type 2 diabetes is not a valid indicator of quality of care. A cross-sectional study. Fam Pract 2003; 20: $173-7$.
[41] Cebul RD, Love TE, Jain AK, Hebert CJ. Electronic health records and quality of diabetes care. N Engl J Med 2011; 365: 825-33.

Received: August 02, 2012

Accepted: September 05, 2012

(C) Al-Lawati et al.; Licensee Bentham Open.

This is an open access article licensed under the terms of the Creative Commons Attribution Non-Commercial License (http://creativecommons.org/licenses/ by-nc/3.0/) which permits unrestricted, non-commercial use, distribution and reproduction in any medium, provided the work is properly cited. 